\title{
A CONTRIBUIÇÃO DA PSICOLOGIA HISTÓRICO-CULTURAL PARA O ENSINO E A EDUCAÇÃO
}

\section{THE CONTRIBUTION OF HISTORICAL-CULTURAL PSYCHOLOGY TO TEACHING AND EDUCATION}

\author{
Taina Pereira ${ }^{1}$ \\ Ademir Damazio $^{2}$
}

\begin{abstract}
Resumo: O presente trabalho se constituiu como estudo bibliográfico no âmbito da Teoria da Atividade e Psicologia Histórico-Cultural (PHC). O objetivo é apontar elementos fundamentais da PHC que contribuem no processo de organização do ensino escolar. A base de análise foi a literatura em três instâncias: 1) dois clássicos da Teoria Histórico-Cultural, Vigotski e Leontiev; 2) uma estudiosa que conviveu com os pesquisadores da terceira geração, Shuare; 3) e estudiosos atuais da referida teoria, Dusavitskii e Bertoldo. Dusavitskii (2014) destaca que uma das principais contribuições dessa teoria é seu pressuposto de que é papel da escola o desenvolvimento da personalidade nas máximas potencialidades. Os estudos de Vigotski (2000), precursor da Psicologia Histórico-Cultural, anteciparam questões fundamentais para psicologia, que contribui na atualidade para a educação. Shuare (1990) expõe temas e conceitos como: os níveis de desenvolvimento e zona de desenvolvimento proximal. Por sua vez, Leontiev, no contexto da Teoria da Atividade compreende a educação como um processo sócio histórico de objetivação/apropriação (BERTOLDO, 2010). Dentre as contribuições dessa teoria, destaca-se a concepção de que a educação e o ensino são meios para o desenvolvimento do homem, em suas máximas possibilidades, principalmente no que diz respeito às funções psicológicas superiores, à personalidade e à consciência. Por decorrência, surge a psicologia pedagógica como uma unidade de duas áreas do conhecimento humano.
\end{abstract}

Palavras-chave: Educação. Ensino. Histórico-Cultural

\begin{abstract}
The present work was constituted as a bibliographic study in the scope of "Theory of Activity and Historical-Cultural Psychology (PHC)". The objective is to point out fundamental elements of PHC that contribute to the process of organizing school education. The basis of analysis was to the literature in three instances: 1) two classics of the Historical-Cultural Theory, Vigotski and Leontiev;

2) a scholar who lived with third-generation researchers, Shuare; 3) and current scholars of this theory, Dusavitskii and Bertoldo. Dusavitskii (2014) points out that one of the main contributions of this theory is that the role of the school is to develop a personality in its maximum potential. The studies of Vigotski (2000), forerunner of Historical-Cultural Psychology, anticipated fundamental questions for psychology, which currently contributes to education. Shuare (1990) discusses themes and concepts such as: development levels and proximal development zone. In turn, Leontiev, in the context of Activity Theory, understands education as a socio-historical process of objectification / appropriation (BERTOLDO, 2010). Among the contributions of this theory is the conception that education and teaching are means for the development of man, in his maximum possibilities,

\footnotetext{
${ }^{1}$ Mestranda pela Universidade do Extremo Sul Catarinense - UNESC - Criciúma/SC, Brasil.

${ }^{2}$ Doutor pela Universidade Federal de Santa Catarina e professor da Universidade do Extremo Sul Catarinense - UNESC

- Criciúma/SC, Brasil.
} 


\section{Universidade do Extremo Sul Catarinense \\ Revista Ibero-Americana de Humanidades, Ciências e \\ Educação \\ unesc

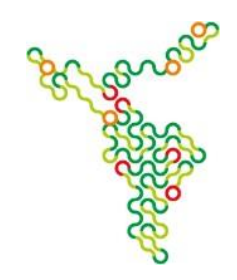

especially with respect to the higher psychological functions, the personality and the conscience. As a result, pedagogical psychology emerges as a unit of two areas of human knowledge.

Keywords: Education. Teaching. Historical-Cultural

\section{Introdução}

O trabalho se consolidou com base em uma disciplina optativa do Programa de Pós-Graduação em Educação da Universidade do Extremo Sul Catarinense (UNESC). Estendeu-se por todo o segundo semestre de 2017. A disciplina tinha como objetivo promover o debate sobre a Psicologia Histórico-Cultural com ênfase na teoria da atividade e suas implicações no processo de organização do ensino que promova o desenvolvimento do pensamento teórico.

Foi no âmbito de sua bibliografia que suscitou a possibilidade de organização do ensino diferente daquela que está posta na prática pedagógica escolar, basicamente do mundo inteiro (DAVÍDOV, 1988). Elas acenam e assinalam objetivamente para uma estruturação de um modo geral de organização do ensino em condições de promover, nos estudantes, o desenvolvimento, em especial de suas funções psicológicas superiores (atenção voluntária, memória lógica, conceito, pensamento, palavra). Nesse contexto, é que se apresentou a formulação do problema de estudo: quais elementos conceituais da PHC são indicados como essenciais para a organização do ensino que atenda sua premissa de desenvolvimento da personalidade e do pensamento teórico? Por extensão, temos como objetivo, neste trabalho, apontar elementos fundamentais da PHC que contribuem no processo de organização do ensino escolar.

Para tratar o objeto da pesquisa, como anunciamos anteriormente, utilizamos algumas das obras literárias de autores que estudam essa teoria. Portanto, trata-se de um estudo de caráter bibliográfico. Dessa forma, elencamos como base para análise a literatura em três instâncias: 1) dois clássicos da PHC, Vigotski e Leontiev; 2) uma estudiosa que conviveu com os pesquisadores da terceira geração, Shuare; 3) e estudiosos atuais da referida teoria, Dusavitskii e Bertoldo. A opção por esses estudiosos do tema ocorreu muito mais pela possibilidade de contado com três gerações de teóricos da PHC que dessem subsídio para a compreensão da possibilidade dessa teoria em relação à educação. 


\section{Universidade do Extremo Sul Catarinense \\ Revista Ibero-Americana de Humanidades, Ciências e \\ Educação \\ unesc

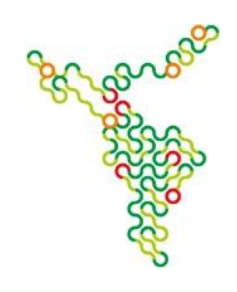

\section{A Teoria Histórico-Cultural e Educação}

Pensar em educação fundamentada em uma determinada perspectiva teórica, no nosso caso a PHC, emerge a necessidade de compreender uma série de elementos, conceitos e princípios essenciais que expressam sua finalidade. No presente estudo, partiu-se do pressuposto prévio de que tal finalidade se refere ao desenvolvimento humano em suas máximas possibilidades, isto é, naquilo que de mais atingiu a humanidade. Esses elementos serão destacados, ao longo desse trabalho, a fim de explicitar como a PHC reconhece a importância decisiva da educação sobre o desenvolvimento do homem e, por extensão, da sociedade.

Nesse sentido, o artigo "Educação desenvolvente e a sociedade aberta", A.K Dusavitskii (2014), destaca como um modo de alerta de que, mesmo estudiosos e políticos sabendo da importância da educação, ela encontra-se em uma situação crítica, em apuros. O autor menciona a reforma da escola ocorrida nos países pós-soviéticos para tentar explicar o que conduziu ao estudo de um novo sistema de ensino. Considera que um dos pontos negativos da reforma foi não considerar as leis psicológicas do desenvolvimento das crianças relacionado à idade. Isso significa que deixou de considerar a idade psicológica, no contexto do desenvolvimento de suas funções psíquicas superiores, para centrar apenas na influência da sua relação com o tempo cronológica e maturacional. Logo, tem a idade de um indivíduo como universal, isto é, o desenvolvimento biológico como determinante para as condições de aprendizagem. Como consequência, o desenvolvimento da criança é considerado normal se corresponder precisamente a sua idade psicológica em determinado tempo de vida. Fora disso, é inevitável conflitos entre ela e a sociedade.

Não se trata, pois, do aspecto social, mas do desenvolvimento psicológico em cada idade, $o$ problema da identidade pessoal em cada fase específica, ou seja, se espera que em cada momento da vida, a criança saiba quem ela é.

Por decorrência, nas escolas atuais, vê-se a imprecisão da idade como fator objetivo. Sendo assim, qualquer mudança no quadro pedagógico de uma escola não faz nenhuma diferença, pois o conhecimento está sendo transmitido aos alunos de forma que ensina o "como fazer" e não o "porque fazer”. Por exemplo, uma criança sabe ler e escrever, mas não pode e não quer usar esse conhecimento para realizar novas tarefas. Isso ocorre justamente porque sua formação voltou-se para uma atitude pragmática em relação ao mundo, em vez do desenvolvimento da personalidade capaz de transformar. Ou seja, o ensino e educação não se preocuparam com desenvolvimento psicológico da criança, isto é, com a formação do psiquismo em toda a sua abrangência. 


\section{Universidade do Extremo Sul Catarinense \\ Revista Ibero-Americana de Humanidades, Ciências e \\ Educação \\ unesc

A idade como fator objetivo é algo que também ocorre no contexto escolar brasileiro, nos dias atuais. Isso se percebe, nas consequências das mudanças do quadro pedagógico, dos materiais, da organização institucional de uma escola não fazem grande diferença na aprendizagem dos estudantes, pois o conhecimento é transmitido aos alunos, isto é, apenas lhes é ensinado "como fazer" e não o “por que fazer”. Expressão disso é o desinteresse dos estudantes pelo estudo. Os estudantes “aprendem" certos conhecimentos, mas não se interessam em realizar novas tarefas em que eles sejam exigidos que caracterizasse o seu processo de desenvolvimento (MARTINS, 2013). Isso ocorre pela formação de uma atitude pragmática em relação ao mundo nos escolares, do não desenvolvimento da personalidade nas máximas capacidades, de uma consciência por consequência de uma apropriação dialética das determinações sociais humanas, isto, do desenvolvimento do sujeito (LEONTIEV, 1978).

Como resultado, segundo Dusavitskii (2014), a desigualdade e competição se tornam explícita e as pessoas são divididas entre capazes e superdotados, bem como em inteligentes e não muito. No contexto da educação da Rússia, ocorre, ao invés de uniformidade soviética, se coloca uma multiformidade, em que se esvazia a possibilidade de um sistema de educação ter um sentido, um significado, uma forma e conteúdo.

Nesse âmbito, ainda é emergente a necessidade de um novo paradigma de educação, de acordo com os reais problemas do mundo contemporâneo, que se expressa em alguns livros, como a educação desenvolvente. Trata-se de uma concepção de educação pautada nos princípios do materialismo histórico-dialético, isto é, que considera a prática social como ponto de partida e de chegada. Nessa direção, os autores dessa teoria realizaram e persistem com experimentos formativos escolares em escolas escolhidas para tal finalidade.

Dusavitskii (2014) aponta como principal, dentre as mudanças qualitativas nesses experimentos, o desenvolvimento da personalidade. Isso porque, nos estudantes, se formaram novos valores, com base no conhecimento científico e na cooperação. Na situação da atividade de estudo, nessas classes experimentais, se formou um ambiente próprio de aprendizagem, em que o aluno é sujeito e objeto da sua própria atividade, criadora do seu meio. "Nessas condições, a turma da escola se transforma em uma autêntica célula da sociedade civil, é aberta ao mundo capaz de exercer influência sobre a transformação desse mundo.” (DUSAVITSKII, 2014, p.81). 


\section{Universidade do Extremo Sul Catarinense \\ Revista Ibero-Americana de Humanidades, Ciências e \\ Educação \\ unesc

De acordo com Shuare (1990), uma das características desse sistema de ensino é sua base filosófica, que assume a concepção marxista da atividade humana e a PHC de Vigotski. Em seu livro A psicologia soviética tal como a vejo ${ }^{1}$ (SHUARE, 1990) evidencia as contribuições significativas para compreensão da PHC. Sua maior referência é ao legado de Vigotski para o desenvolvimento da psicologia. Destaca que suas obras parecem ter sido escritas nos tempos atuais, pois, suas ideias, mesmo sendo contemporâneas e articulas com a revolução russa de 1917 e dela teve influência, antecipou questões fundamentais da psicologia. "Dizer que Vigotski abriu uma nova caminhada na psicologia é pouco. Sua concepção definiu e define até hoje (e, cremos, por muitos anos ainda) a direção mais frutífera do desenvolvimento da psicologia soviética” (SHUARE, 1990, p. 58).

Em sua teoria, o eixo central para compreendê-la é o historicismo, pois é a partir dele que se organiza e gera os demais conceitos. Desse modo, a autora aponta três gerações conceituais a partir do historicismo: tempo; psique humana como social; e o caráter mediatizado da psique humana.

A geração conceitual de tempo é colocada com o sentido de existência da matéria, como algo mais que abstrato. Insere-se no contexto da história, seja individual ou social, isto é, como o processo de desenvolvimento da sociedade. Nesse sentido, a atividade produtiva e transformadora do homem é a referência para compreensão do desenvolvimento social. O processo de transformação acontece na relação do homem com a natureza no âmbito da finalidade de superação de suas necessidades. Para tanto, requer construção de instrumentos, que se constituem como mediadores da relação entre o homem e a natureza. Com isso, os instrumentos se constituem como cultura, pois carregam em si os procedimentos historicamente produzidos da referida relação.

No que diz respeito à geração conceitual da psique humana como social, Shuare (1990) diz que Vigotstki considera os fenômenos psíquicos como algo não pronto, estático. Pelo contrário, existe uma relação de dependência desses fenômenos com a atividade que o sujeito realiza no conjunto das relações sociais. Entretanto, o social não condiciona o psíquico de forma determinada, de maneira direta nas estruturas orgânicas. O entendimento é de que se institui como essência atrelada à história da psique humana, isto é, a história social de sua constituição. Uma vez constituído, o sujeito em desenvolvimento, se apropria dela.

Por fim, a terceira geração conceitual, a partir do historicismo, é a do caráter mediatizado da psique humana. A autora firma que a psique humana é produto da interação do indivíduo com o

\footnotetext{
${ }^{3}$ Texto em espanhol, tradução nossa.
} 


\section{Universidade do Extremo Sul Catarinense \\ Revista Ibero-Americana de Humanidades, Ciências e \\ Educação \\ unesc

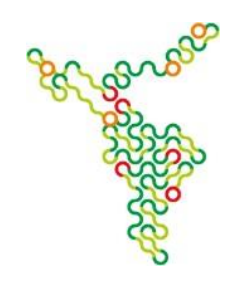

mundo, mediatizada pelos objetos criados pelo homem. Portanto, diferente da psique "natural" do animal, que se estabelece na relação direta com a natureza, sem mediações, a fim de satisfazer apenas as necessidades imediatas. Dessa forma, supera-se a ideia da psicologia tradicional da psique como algo interno ao sujeito, como processo natural ao invés de social.

Para tanto, conforme Shuare (1990) exige-se a compreensão de uma série de conceitos pertinente à teoria vigotskiana. Dentre eles, os conceitos de instrumento e signo, uma vez que ambos têm função de mediatização. Porém, existem diferenças entre ele, pois o instrumento é o responsável por provocar mudanças no objeto da atividade. Diferentemente, o signo não muda o objeto, mas é meio da ação psicológica sobre o comportamento.

Ao entender o desenvolvimento das funções psíquicas desta maneira, que ocorre num processo mediado, Vigotski afirma que as funções psíquicas na criança aparecem duas vezes. O primeiro se dá no processo interpsicológico, que acontece no plano social, em que a atividade é desenvolvida com ajuda de outra pessoa. A segunda vez que tal função aparece é quando o sujeito internaliza algo, isto é, um processo intrapsicológico.

Para Shuare (1990) o estudo da relação interpsicológico e intrapsicológico é fundamental para a compreensão do desenvolvimento humano enquanto ser social. Isso porque a criança, desde os primeiros anos de vida tem acesso às coisas por meio de outra pessoa e, nesse processo interativo e mediado por signo, que ela se desenvolve.

Mas as contribuições de Vigotski, segundo Shuare (1990) não para por aqui. Outra, que teve significativa relevância com implicações para o ensino, foram as pesquisas referentes à defectologia (estudo da aprendizagem da criança com deficiência). A defectologia tem por objeto a especificidade de fenômenos qualitativos que possui na criança com "defeito" (termo utilizado no período dos estudos de Vigotski). Nesse sentido, Vigotski aponta que os estudos desse objeto devem ser entendidos como um problema social, e não como um fenômeno somente físico. Dito com outros termos, é necessário pensar as deficiências para além das questões físicas, por exemplo, que pessoas cegas têm apenas a falta de visão. Superar esse reducionismo significa o entendimento de que isso vai mais além, isto é, significa a perda das funções sociais, uma vez que a comunicação como fator social será prejudicada. 


\section{Universidade do Extremo Sul Catarinense \\ Revista Ibero-Americana de Humanidades, Ciências e \\ Educação \\ unesc

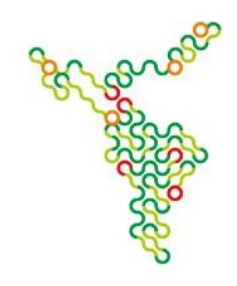

Além disso, Shuare (1990) ressalta os estudos sobre a consciência como problema da psicologia. Na investigação sobre consciência, Vigotski a toma como objeto de estudo e, por meio de seu método genético experimental, busca novos princípios para compreendê-la.

Shuare (1990) considera que as colaborações de Vigotski são fundamentais para educação, haja vista que ele conclama pela necessidade de se compreender o desenvolvimento da psique humana, como condição para o processo de organização do ensino.

Sobre o tema consciência, o livro "O Desenvolvimento Do Psiquismo" - no capítulo II “Aparecimento Da Consciência Humana” - do autor Alexis Leontiev (2004) é uma das referências.

Leontiev (2004) concebe a consciência como um estágio superior do psiquismo. Entende que “o reflexo consciente, diferentemente do reflexo psíquico próprio do animal, é o reflexo da realidade concreta destacada das relações que existem entre ela e o sujeito, ou seja, um reflexo que distingue as propriedades objetivas estáveis da realidade.” (LEONTIEV, 2004, p. 75).

Leontiev (2004) destaca que as condições do aparecimento da consciência humana se apresentam como produto e condição do desenvolvimento do trabalho. Esclarece que, com o desenvolvimento do trabalho, houve transformações no cérebro, dos órgãos de atividade externa, isto é, dos órgãos do sentido. Com isso, o desenvolvimento do trabalho teve dupla transformação no homem: nas condições de seu biológico e do seu psicológico. O aumento do tamanho do cérebro expressa o desenvolvimento do homem em seus aspectos biológicos. Ou seja, a transformação da estrutura cerebral decorre do processo de desenvolvimento psíquico do homem. Portanto, a categoria trabalho é a base ontológica do desenvolvimento do homem, seja nos seus aspectos naturais ou sociais.

Sendo assim, a categoria trabalho é centralidade para entendimento do processo de humanização. Karl Marx explica o trabalho como a relação entre o homem e a natureza, em que o homem põe em movimento a natureza a fim de dar vida útil, ou valor de uso, aos seus elementos, para suprir suas necessidades. Nesse processo ocorre dupla objetivação, em que o homem modifica a natureza e ao mesmo tempo modifica-se, ou seja, desenvolve suas funções psicológicas. Este processo é caracterizado pelo uso e construção de instrumentos na atividade realizada em condições coletivas (LEONTIEV, 2004).

Portanto, o trabalho é atividade que dela se origina todas aquelas que sugiram no processo de desenvolvimento da humanidade e, por consequência, do psiquismo, da consciência. Isso nos remete 


\section{Universidade do Extremo Sul Catarinense \\ Revista Ibero-Americana de Humanidades, Ciências e \\ Educação \\ unesc

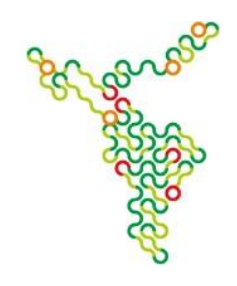

à necessidade de compreensão da estrutura da atividade e de suas mudanças, que ocorrem no âmbito do coletivo. Durante o desenvolvimento humano, ocorre à forma primitiva de divisão técnica e social do trabalho, o que leva à formação da estrutura fundamental da atividade humana. Para expor sobre o surgimento e desenvolvimento da atividade, Leontiev se utiliza do exemplo da caçada, em que as pessoas, nela envolvidas, realizavam ações diferentes: abater o animal, espreitá-lo, enxotá-lo, apanhálo. Nessa divisão do trabalho, todos se encontram na mesma atividade, com os mesmos motivos, mas como dito, cada um possui ações diferentes. Portanto, elas em si não suprem a necessidade de imediato, mas em seu conjunto, chegam à satisfação da necessidade daquela atividade: a alimentação, condição de existência. Assim, aquilo que o indivíduo está orientado a realizar é o motivo de sua atividade. Nesse caso, chama-se ações o aparato humano em atividade em que objeto e motivo são separados. Leontiev (2004) explicita a estrutura da atividade humana como constituída dos seguintes componentes: necessidade, motivo, sentido, significado, finalidade, tarefas, ações, operações. Davídov (1988) entende a estrutura da atividade teorizada por Leontiev constituída por componentes estruturais e seus correlatos em um processo dinâmico e transformativo. Isso pode ser sintetizado da seguinte forma: 1) componentes essenciais em transformação, necessidade $\rightleftarrows$ motivo $\rightleftarrows$ finalidade $\rightleftarrows$ condições; 2) componentes estruturais correlatos, atividade $\rightleftarrows$ ação $\rightleftarrows$ operação. Isso significa que a transformação de um componente essencial em outro implica na formação, por exemplo, de uma nova atividade ou desta passar a ser uma ação (LEONTIEV, 2004; DAVÍDOV, 1988).

Leontiev (2004) salienta que o homem se diferencia do animal porque satisfaz suas necessidades por meio da atividade. Por sua vez, o animal se limita à satisfação de apenas as necessidades imediatas, instintivas, isto é, não requer uma prévia ideia ou uma finalidade estabelecida antecipadamente. A relação do animal com a natureza é extremamente natural é puramente instintiva. Enquanto esse tipo de relação no homem é objetiva social. Por exemplo, o resultado final da caçada se dá na relação do indivíduo com os outros membros. Cada um recebe sua parte do produto da atividade do trabalho coletivo, quer dizer, o objeto e o motivo não se objetivam pelo natural, mas pela relação objetiva social. Por extensão, isso explica a origem, especificadamente humana, do reflexo da realidade, isto é, a consciência.

De acordo com Leontiev (2004), o trabalho modifica a estrutura da atividade humana, transforma as operações em seu meio/condições. Isso ocorre com o desenvolvimento dos instrumentos, cuja construção e utilização só são possíveis tendo consciência do final da ação do 


\section{Universidade do Extremo Sul Catarinense \\ Revista Ibero-Americana de Humanidades, Ciências e \\ Educação \\ unesc

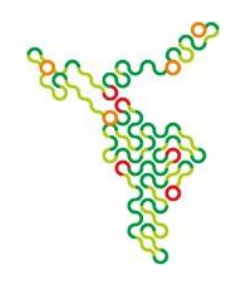

trabalho. Dessa forma, o instrumento não é algo apenas físico, mas também um objeto com significado, atribuído socialmente de acordo com o trabalho coletivo.

Bertoldo (2010) retoma a Teoria Histórico-Cultural e fornece elementos fundamentais para o desenvolvimento de uma concepção de educação voltada para a perspectiva marxista. Parte do estudo de Vigotski e dos pressupostos do ser social de Marx. Por isso, centra-se na análise da educação a partir das ideias de Leontiev, que podem ser conferidas em seu artigo "A concepção marxista de educação em Leontiev".

A princípio, a autora coloca a educação como um processo sócio-histórico de objetivação/apropriação, isto é, o "[...] importante papel da educação no processo de desenvolvimento do gênero humano" (BERTOLDO, 2010, p. 203). Esse processo é entendido, a partir das ideias bases que apoiam essa teoria, ou seja, da categoria ontológica do ser social: o trabalho. Para tanto, refere-se a Marx ao afirmar o trabalho como responsável do desenvolvimento do ser humano que, necessariamente, se estabelece a relação entre a teleologia (processo que idealiza a finalidade de uma ação) e a causalidade (necessidade emergente). Nesse sentido, o trabalho surge como uma atividade que se realiza com a existência de uma consciência orientada.

Esses dois elementos - teleologia e causalidade - são importantes no processo de produção, uma vez que algo só se constituí a partir da relação dinâmica entre eles. Dessa forma, na finalidade (teleologia) se vincula a um fim e se revela em algo material ou ideal. Nesse âmbito, aparece outro elemento conceitual correspondente: a objetivação, isto é, o trabalho que se fixou em um objeto transformado em objeto físico ou espiritual (BERTOLDO, 2010).

De acordo com a autora, Marx considera a objetivação como o momento efetivo do processo de trabalho. Porém, não apenas como resultado das necessidades biológicas (alimentação, vestimenta etc.), mas também daquilo que o homem necessita no âmbito social, como a arte, poesia, música etc., isto é, objetivações humanas ou produções humano-genéricas. Trata-se, pois do reflexo da relação homem-natureza, mediada pelo trabalho, que ambos se modificam e se transformam.

É nesse contexto que Bertoldo (2010) explica a educação como uma necessidade humana, que tem origem no processo de desenvolvimento humano, como pôr-teleológico secundário. Sendo assim, concebe que o homem não nasce desenvolvido em suas aptidões, mas que são geradas no processo de atividade, de apropriação/objetivação. No caso da educação, esse processo de apropriação se dá na relação interpsicológico, isto é, as produções humanas são transmitidas pelas gerações 


\section{Universidade do Extremo Sul Catarinense \\ Revista Ibero-Americana de Humanidades, Ciências e \\ Educação \\ unesc

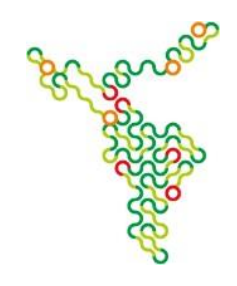

antecedentes para mais novas que, ao ser apropriadas, tornam-se intrapsicológicas. Isso significa que a assimilação de um conhecimento, pelo estudante, ocorre no processo de aprendizagem, ou seja, acontece o processo de assimilação/apropriação (BERTOLDO, 2010). Diríamos, num contexto de atividade.

Para Bertoldo (2010), Leontiev considera o trabalho não apenas sob a ótica de suas objetivações, mas também a apropriação, pelos indivíduos, das capacidades humanas nelas reveladas. Uma criança nasce num mundo de objetivações humanas, carregadas de capacidade e significados. Na posição social que ocupa, naquele momento, apropria-se dessas produções humanas por meio de uma atividade peculiar.

A partir disso, Bertoldo (2010) coloca que o processo de apropriação, em primeiro lugar, é uma condição para o desenvolvimento do indivíduo como ser social. Em segundo lugar, se dá pelas relações sociais, que são determinadas pela forma de vida nas condições materiais. "Portanto, é através da educação, que é um processo de apropriação, que o homem se desenvolve se humaniza, se torna cada vez mais homem." (BERTOLDO, 2010, p. 201).

Contudo, mesmo Leontiev colocando tamanha importância à educação, ele não atribui à responsabilidade apenas nela para a formação plena do homem. De acordo com Bertoldo (2010, p. 203), "para Leontiev, o desenvolvimento pleno das capacidades humanas só poderá se efetivar numa sociedade emancipada e, para isto, é necessário que se dê a total dissolução do capitalismo. É este, ao fim e ao cabo, que impõe limites insuperáveis ao total desenvolvimento do gênero humano".

Conforme a autora, em nosso país - dividido em classes - isso fica explícito. Há sempre uma luta de classes entre dominantes e dominados, trabalhadores e capitalistas, em que cada uma delas defende seus interesses e, por extensão, o desenvolvimento das potencialidades do homem torna-se “exprimida”, sempre direcionada pelo pragmatismo do mundo do trabalho.

Isso significa, a partir de nossas reflexões, que o pleno desenvolvimento do homem só é possível com o rompimento da propriedade privada, que estabelece valores de troca às produções humanas. No entanto, esses valores não são acessíveis à maioria da população, que se alienam dessas produções. Então, uma questão se apresenta: Nas atuais condições, é possível uma educação para o pleno desenvolvimento humano? Ou, homem teria possibilidades e liberdade para desenvolver-se nas máximas potencialidades? Nesse sentido, recorremos a Leontiev (1978, p. 284), ao afirmar que:

O verdadeiro problema não está, portanto, na aptidão ou inaptidão das pessoas para se tornarem senhores das aquisições da cultura humana, fazer delas aquisições da sua 
personalidade e dar-lhe a sua contribuição. O fundo do problema é que cada homem, cada povo tenha a possibilidade prática de tomar o caminho de um desenvolvimento que nada entrave. Tal é o fim para o que deve tender agora a humanidade virada para o progresso. Este fim é acessível. Mas só o é em condições que permitam libertar realmente os homens do fardo da necessidade material, de suprimir a divisão mutiladora entre trabalho intelectual e trabalho físico, criar um sistema de educação que lhes assegure um desenvolvimento multilateral e harmonioso que dê a cada um a possibilidade de participar enquanto criador em todas as manifestações da vida humana.

Diante disso, a educação se põe em um lugar essencial, como espaço de luta que, mesmo não sendo ela sozinha a salvadora, mas é possibilidade de objetivação e apropriação das produções humanas.

\section{Considerações finais}

O estudo da bibliografia, prevista para o presente estudo, traz evidência de componentes da Teoria Histórico-Cultural e Teoria da Atividade para a organização do ensino e a educação. Dusavitskii (2014), Shuare (1990), Leontiev (1978; 2004) e Bertoldo (2010) estudiosos das referidas teorias, mesmo em diferentes momentos e contextos, continuam unânimes em afirmar que é papel da educação e do ensino o desenvolvimento das funções psíquica superiores, da psique e da consciência dos estudantes. Então, é possível dizer que os sistemas de ensino, na atualidade, não cumprem essa finalidade? A questão é respondida por Davídov (1988) de modo afirmativo e negativo. Afirmativamente quando diz que esse desenvolvimento ocorre, mas com conteúdo empírico. Consequentemente, a resposta negativa está por não propiciar o desenvolvimento em suas máximas capacidades, em nível teórico. E, sendo assim, é possível dizer que, dadas às condições objetivas impostas pelas relações sociais de produção, é negado aos estudantes à oportunidade de apropriação dos conceitos científicos. Ou seja, aqueles que realmente promovem a formação do pensamento teórico.

Os autores referenciados expõem a complexa conceituação da teoria de Vigotski que se centra na formação das funções psicológicas superiores e da consciência - tanto entre os estudantes tidos com 'normais' como 'com defeitos' - como resultantes do processo de atividade humana. Nesse sentido, Leontiev traz contribuição ao vincular a teoria da atividade à categoria de trabalho na perspectiva de Marx. Nesse âmbito, emerge a concepção de que a educação traz importante contribuição para os estudos relacionados ao desenvolvimento do homem. Contudo, não se pode perder de vista que, para atingir o pleno das capacidades humanas - nos estudantes, no homem - é 


\section{Universidade do Extremo Sul Catarinense \\ Revista lbero-Americana de Humanidades, Ciências e \\ Educação \\ UnesC Produção e democratização do conhecimento na lbero-América}

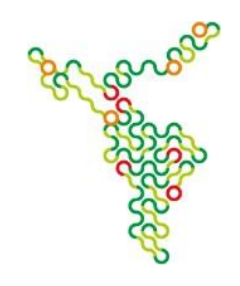

condição a superação das sociedades divididas em classe sociais distintas, com diferentes necessidades e motivos em suas atividades.

Diante disso, essas teorias se constituem em referências para estudos e investigações experimentais - traduzidos em artigos, teses, dissertações, etc. - que apontem significativas contribuições para se pensar a educação, em especial o ensino, mesmo num contexto contraditório, dada as relações sociais imperativas na atualidade brasileira e mundial.

\section{Referências}

BERTOLDO, Edna. A concepção marxista de Educação em Leontiev. In: Revista Eletrônica Arma da Crítica, ano 2, número especial, dezembro de 2010, p.189-204.

DAVÍDOV, V. V. La enseãnza escolar y el desarrollo psiquico: investigación psicológica teórica y experimental. Moscu: Editorial Progreso, 1988.

DUSAVITSKII, A.K. Educação desenvolvente e a sociedade aberta. In: Ensino Em Re-Vista, v.21, n.1, p.77-84, jan./jun. 2014.

LEONTIEV, A. O desenvolvimento do psiquismo. Lisboa: Livros Horizonte, 1978.

. Aparecimento da consciência humana. In: LEONTIEV, A. O desenvolvimento do

Psiquismo. São Paulo: Editora Moraes, Capítulo II, p. 75-94, 2004.

MARTINS, L.M. O desenvolvimento do psiquismo e a educação escolar: contribuições à luz da psicologia histórico-cultural e da pedagogia histórico-crítica. Campinas, SP: Autores Associados, 2013.

SHUARE, Marta. La concepción Histórico-Cultural de L.S. Vigotski. In: SHUARE, Marta. La psicologia soviética tal como yo la veo. Moscou: Edotorial Progreso, Capítulo III, p. 57-84, 1990.

VIGOTSKI, L. S. A. A construção do pensamento e da linguagem. São Paulo: Martins Fontes, 2000. 